\title{
Some problems of analysis of types and forms of complicity in international criminal law
}

\section{Yu. O. Goncharova ${ }^{1}$}

${ }^{1}$ P. G. Demidov Yaroslavl State University, 14 Sovetskaya str., Yaroslavl 150003, Russian Federation

DOI: $10.18255 / 1996-5648-2021-3-408-417$

Research article

Full text in Russian

The article deals with certain issues of the institution of complicity in international criminal law, presents the genesis of the phenomenon of complicity, taking into account the variety of sources of international criminal law. The author notes the positive and negative aspects in the formation of doctrinal and interpretive views on the problems of assessing complicity in international crimes. The current tense political situation in the world, the constant increase in the number of terrorist groups, the increase in smuggling, drug trafficking and a number of other criminal factors are prerequisites for increasing attention to the problem of complicity in international crime. In international criminal law, the concept of "complicity" in a crime is in many ways similar to that developed in the criminal law doctrine, legislation and investigative and judicial practice of many States. Obviously, the commission of a crime in complicity poses a much greater public danger than the commission of a crime by one person. Since the definition of complicity in a crime in the commission of an international crime is generally similar to the national definition, in order to identify the signs that are inherent in complicity in the crime, the author refers to the provisions of article 32 of the Criminal Code of the Russian Federation. However, differences in theoretical and enforcement assessments of complicity in international and domestic legal practice require analysis of this situation of affairs. At present, the institution of complicity is constantly improving and developing, but proper scientific research on the content and nature of this development is not carried out at both the national and international levels.

Keywords: international criminal law, international crime, criminal responsibility, complicity, role-sharing, criminal organization, criminal community, criminal conspiracy

\section{INFORMATION ABOUT AUTHORS}

\begin{tabular}{l|l} 
Goncharova, Yuliya O. & $\begin{array}{l}\text { E-mail: julygoncharova97@yandex.ru } \\
\text { Postgraduate }\end{array}$
\end{tabular}

This is an open access article under the CC BY license (https://creativecommons.org/licenses/by/4.0/) 


\section{Некоторые проблемы анализа \\ видов и форм соучастия \\ в международном уголовном праве}

\section{Ю. О. Гончарова ${ }^{1}$}

${ }^{1}$ Ярославский государственный университет им. П. Г. Демидова, ул. Советская, 14, Ярославль, 150003, Российская Федерация

DOI: $10.18255 / 1996-5648-2021-3-408-417$

УДК 341.46

Научная статья

В статье исследуются некоторые аспекты института соучастия в международном уголовном праве, рассмотрено развитие и содержание феномена соучастия на основе многочисленных источников международного криминального законодательства. Автор отмечает позитивные и негативные аспекты в формировании доктринальных и интерпретационных взглядов на проблемы оценки соучастия в международных преступлениях. Существующая сложная политическая мировая палитра, регулярный рост количества террористических сообществ, увеличение контрабандных проявлений, оборота наркотических средств и существование иных криминогенных фракторов определяют основания для возрастания интереса к исследованию вопросов соучастия в совершении международных преступных посягательств. В международном уголовном праве определение «соучастия» в преступлении в значительной степени дублирует понятие, которое сформировалось в теории уголовного права, законодательстве и следственно-судебной практике значительного количества стран. Действительно, совершение группового преступления содержит существенно большую общественную опасность, чем преступление, совершенное единолично. Поскольку определение соучастия в преступлении в совершении международного преступления в целом сходно с национальным определением, для выявления признаков, которые присущи соучастию в преступлении, автор обращается к положениям статьи 32 УК РФ. Тем не менее имеющиеся различия в теоретических и правоприменительных оценках соучастия в международной и отечественной юридической практике требуют анализа такого положения вещей. В настоящее время институт соучастия постоянно совершенствуется и развивается, однако должного научного исследования содержания и характера этого развития не осуществляется как на национальном, так и на международном уровне.

Ключевые слова: международное уголовное право; международное преступление; уголовная ответственность; соучастие; распределение ролей; преступная организация; преступное сообщество; преступный заговор

\section{ИНФОРМАЦИЯ ОБ АВТОРАХ}

$$
\begin{array}{l|l}
\text { Гончарова, Юлия Олеговна } & \begin{array}{l}
\text { E-mail: julygoncharova97@yandex.ru } \\
\text { Аспирант }
\end{array}
\end{array}
$$

() Гончарова Ю. О., 2021

Статья открытого доступа под лицензией СС ВY (https://creativecommons.org/licenses/by/4.0/) 
Несмотря на довольно высокую степень развития как доктрины международного уголовного права, так и практики работы международных трибуналов и судов в настоящее время достаточно сложной является проблема определения видов и фрорм соучастия в совершении преступлений против мира и безопасности человечества. Доктрина международного уголовного права насыщена разнообразными классификациями видов соучастия, которые дифференцируются как в связи с привязкой к той или иной правовой семье, так и по отнесению к различным государственным юрисдикциям [1, с. $56 ; 2$, с. 112]. Тем не менее официально признанными и внедренными в правоприменительную практику во многих государствах считаются (если использовать отечественную доктринальную терминологию) три основных вида: простое соучастие (соисполнительство), сложное соучастие или соучастие с распределением ролей, преступная организация.

Очевидно, что для некоторых международных преступлений, таких как наркоторговля, подделка денег и ценных бумаг, контрабанда, работорговля возможны варианты совершения и в форме простого соучастии, когда соучастники совместно непосредственно выполняют действия, которые и образуют объективную сторону данных преступлений. В такой ситуации соисполнители могут совершать конкретные совместные согласованные преступные действия фактически, в реальном времени, например, несколько субъектов осуществляют непосредственное незаконное перемещение товаров или финансовых инструментов через таможенную границу. Иной вариант предусматривает совершение соучастниками различных альтернативных криминальных деяний, регламентированных в конкретном уголовно-правовом запрете, когда один из соисполнителей незаконно приобретает вооружение, другой осуществляет его сбыт. Третья ситуация предусматривает преступное поведение субъектов, которые поочередно выполняют элементы (этапы) конкретного преступного деяния, например перевозку фальшивых денег или ценных бумаг [3, с. 133]. Отдельно можно выделить варианты соисполнения, когда лица совершают соответствующие преступные (альтернативные или квалифицированные) действия, закрепленные в разных частях определенной статьи уголовного закона [4, с. 121].

Однако следует сказать, что в непосредственном (простом) виде соучастия соисполнительство встречается достаточно редко. Наиболее распространенным видом в международном уголовном праве является соучастие с распределением ролей. В данном виде соучастия выделяются исполнители, организаторы (руководители), подстрекатели и пособники, которые объединены между собой единой целью. В этом случае все субъекты несут ответственность не за отдельные действия, которые соверша- 
ются каждым из них лично, а за всю преступную деятельность, в которой они принимали непосредственное участие, в том числе и в совместном причинении вреда. Эти две разновидности соучастия отражают такую форму, как группа лиц, которая признается теорией международного, отечественного и зарубежного криминального права, и определенным образом регламентированы в законодательстве международного характера.

Третий вид (соучастия) - преступная организация - выступает одновременно и как вид соучастия, и как форма соучастия. Устав Нюрнбергского трибунала (Устав Международного Военного Трибунала для суда и наказания главных военных преступников европейских стран оси) [5] в статье 9 прямо указывает на существование такой фрормы соучастия в международном уголовном праве. Преступные организации, деятельность которых рассматривалась, в частности, Нюрнбергским трибуналом, характеризуются довольно значительным числом членов (например, партийные структуры НСДАП, подразделения СС, СД, гестапо, Генеральный штаб Вермахта и т. д.) Таким образом, в деятельности трибунала родилась потребность в выделении из таких групп непосредственно тех субъектов, которые определяются как самые реальные и активные участники международных преступных посягательств; эти лица выполняли важнейшие необходимые и обязательные властные руководящие или организационные фрунции, отдавали преступные приказы и распоряжения. Существенной в деятельности таких руководителей была задача разграничения и уточнения полномочий, ролей и функций конкретного члена организации и определения меры ответственности каждого из них.

Заметим, что при определении и вычленении элементов и механизмов преступного соучастия в деятельности лиц, причастных к международным и военным преступлениям, Нюрнбергский процесс реализовывал существенную прогрессивную линию.

В итоговом приговоре суда были закреплены три группы субъектов, составляющих преступную организацию: 1) участники организации, которые занимали в ней различные существенные властные руководящие посты, перечисленные трибуналом; 2) иные лица, ставшие членами организации (сообщества) или сохранившие членство в ней, осознавая и понимая, что эта организация была причастна к совершению преступных деяний; 3) субъекты, непосредственно виновные в совершении преступных посягательств и являющиеся членами такой организации. Такие лица привлекались к уголовной ответственности за совершение международных и военных преступлений, а также объявлялись в международный розыск.

В отечественной правовой доктрине указывается на еще одну особую форму соучастия - заговор. Для указанной формы, отмечают правове- 
ды, характерны: а) длительность подготовки преступления, б) включение в число его участников представителей власти, в) глубокая конспирация деятельности, г) посягательство на наиболее важные международные (межгосударственные) отношения, вплоть до захвата власти в суверенных государствах [6, с. 36-37].

Полагаем, что данная позиция имеет право на существование, однако наша оценка данной ситуации предполагает рассмотрение заговора как наиболее особенного вида оперативной деятельности международных преступных сообществ и организаций. Последний характерен для организации и реализации наиболее тяжких международных преступлений. При этом заговор, квалифицируется как отдельное единичное преступление. Заметим, что лица, организующие преступный заговор и осуществляющие подготовку наиболее тяжких международных преступных посягательств, действуют по-иному, чем исполнители и иные соучастники общеуголовных преступлений. Современная глобализация определяет, что заговорщики в отдельных случаях могут находиться на территориях различных стран, часто не являются непосредственно связанными между собой, тем не менее вся их деятельность направлена на реализацию единого последовательного преступного плана, который будет координироваться в большинстве случаев из единого руководящего (часто законспирированного) центра.

Если говорить о содержании существенных и обязательных признаков заговора, то он как одна из форм деятельности международных криминальных сообществ характеризуется целым спектром необходимых элементов: а) реализуется группой лиц, достаточно сплоченной и рассчитанной на длительное существование; б) обычно противостоит иному государству или международной юрисдикции, при этом суверенность иного государства может и не оспариваться; в) предусматривает обстоятельную подготовку и утверждение преступного плана, связанного с насильственным захватом власти внутри государства (на части территории государства, союза государств, международной организации); г) сопровождается подавлением противодействующих сил, а затем и внешней экспансией, осуществляемой в процессе его выполнения; д) отличается глубокой конспирацией, по боьшей части содержит в себе элементы национального предательства, грубейшего нарушения норм национального законодательства, а также международных правовых и обычных обязательств [3, с. 140].

Ряд международных актов выделяет дополнительные фрормы соучастия, например такие, как структурно оформленная группа и организованная преступная группа. Под первой следует понимать группу, которая 
не была случайно образована для немедленного совершения преступления и в которой не обязательно формально определены роли ее членов, особо зафиксирован характер членства или создана развитая структура. Под организованной преступной группой в Конвенции ООН против транснациональной организованной преступности (принята 13.12 .2000 года в Палермо) понимается структурно оформленная группа в составе трех или более лиц, существующая в течение определенного периода времени и действующая согласованно с целью совершения одного или нескольких серьезных преступлений, с тем чтобы получить, прямо или косвенно, фринансовую или иную материальную выгоду [7].

В отношении выделения каких-либо новых фрорм соучастия, отличных по ряду признаков от уже устоявшихся как в литературе, так и на практике, мы занимаем позицию о недопустимости смешивания указанных феноменов. Введение новых форм существенно затруднит процесс работы международных трибуналов по привлечению к ответственности лиц, виновных в совершении международных преступлений, поскольку эти новые виды все-таки являются результатом абстрактной работы конкретных ученых (без апробации их практике). В силу этого считаем полезным и возможным использование на практике трех вышеуказанных фрорм, которые повсеместно приняты доктринально и сопряжены со значительным опытом правоприменения.

Как уже отмечалось, международное уголовное право в части исследования института соучастия находится в постоянном развитии, особую роль в этом процессе играют международные трибуналы. Далее рассмотрим отдельные принятые правоприменительные практики для определения соучастия в международном преступлении. В последние годы в судебно-следственной деятельности положительно была воспринята концепция совместного преступного предприятия (совместной преступной деятельности). Ключевыми элементами данной концепции являются: а) активное стремление всех членов преступного сообщества к достижению оговоренного и согласованного преступного результата; б) существование нескольких членов (два и более) группы, активно и непосредственно участвующих в совершении международного преступления; в) разработка и принятие совместного преступного плана; г) альтернативное (пусть самое минимальное) участие лица в реализации общего преступного плана.

Базовые постулаты и правила указанной концепции закрепил в своем приговоре международный трибунал по бывшей Югославии. При этом суд вычленил три ключевые формы соучастия: а) основную, б) системную и в) расширенную. Стержневым основанием дифференциации названных 
форм определены элементы (признаки) субъективной стороны преступного соучастия. Действительно, это обоснованное решение, поскольку чаще всего элементы объективной стороны соучастия зачастую пересекаются в рамках содеянного. Допустимы случаи, когда эти элементы полностью тождественны.

Далее основательно проанализируем каждую из форм указанного выше соучастия. Очевидно, что наиболее опасной формой группового соучастия является расширенная форма. Применительно к расширенной форме мы можем говорить об ответственности, выходящей за границы совместного криминального плана, в котором эксцессивно могут появляться и нарушать уголовно-правовые запреты иные лица. В каком-то смысле здесь речь идет об объективном вменении, что противоречит отечественной правовой доктрине. Обязательным механизмом такой оценки должно быть допущение (предположение) участником расширенной формы риска (пусть и абстрактного) совершение преступления такими привходящими субъектами. Согласимся, что такая позиция предполагает очень широкое следственное и судебное усмотрение, которое способно значительно ограничить лицо в его гражданских правах и свободах.

Рассмотрим положения приведенной концепции далее. Акт участия субъекта в противоправной деятельности налицо в случае, если это лицо осознает характер, содержание и последствия своих действий, принимает акт участия совместно с осознанным решением участвовать в процессе его реализации. В ситуации, когда оба указанных элемента являются доказанными, субъект должен нести ответственность не только за свои действия, но и за все наступившие в результате таких действия последствия. При таком подходе для квалификации соучастия не требуется обязательного фрактического присутствия лица либо реального физического содействия в процессе противоправной деятельности.

Напротив, в модели международного преступления при основной форме соучастия должен находиться общий совместный умысел (план действий) всех его субъектов-соучастников. В этой ситуации каждый из субъектов отвечает за деяние, в совершении которого он участвовал непосредственно (соисполнение) либо выполнял конкретные функции соучастника, в соответствии с отечественной нормативной и доктринальной позицией, организатора, подстрекателя, пособника. Заметим, что системная форма совместной преступной деятельности, на наш взгляд, развивалась в доктрине и закреплялась на практике для военных преступников, которые жестоко обращались с задержанными, заключенными и осужденными в концентрационных лагерях, тюрьмах, трудовых лагерях и иных местах лишения и ограничения свободы. 
При этом такая концепция в меньшей степени связана с военными преступлениями в период Второй мировой войны, а в большей - с деятельностью послевоенных международных военных трибуналов. $\mathrm{K}$ примеру, в приговорах международного трибунала по бывшей Югославии отмечается, что наряду с лицами (исполнителями), которые непосредственно жестоко обращались с задержанными, несет ответственность и руководитель «пенитенциарного» учреждения, поскольку осознавал преступный характер системы, в которой он осуществлял свой функционал. Мы не случайно взяли в кавычки термин «пенитенциарный», поскольку такие учреждения могли быть созданы как на законной основе, так и помимо неё.

Напомним в этой связи одно из положений приговора международного трибунала по бывшей Югославии: «Чтобы признать обвиняемого уголовно-ответственным за действия, которые являются естественными и обозримыми последствиями объединенного преступного предприятия, нет необходимости устанавливать его фрактическое знание того, что эти действия будут совершены. Достаточно показать, что эти действия, находящиеся вне согласованного преступного предприятия, были естественным и обозримым последствием согласованного преступного предприятия и что обвиняемый участвовал в этом предприятии, зная о вероятности, что эти иные преступления могут быть совершены. Также судебной палате не нужно было устанавливать, что Р. Крстич фрактически знал о совершении этих иных преступных действий; достаточно было показать, что их совершение было ему обозримо и что эти иные преступления в действительности фактически были совершены» [8, с. 4].

Концепция совместной преступной деятельности в современной литературе получила двоякую оценку. С одной стороны, это новое научное изыскание, которое во многом может усовершенствовать практику определения соучастия в преступлении, что повлечет за собой в дальнейшем более справедливые решения в части дифференциации ответственности лиц, совершивших международные преступления. Однако, с другой стороны, данная концепция справедливо критикуется за то, что, по сути, ее нормативные установки сопряжены с широким судебным или правоприменительным усмотрением (как уже упоминалось, легализует принцип объективного вменения), допускают наступление уголовной ответственности за абстрактно предвидимые (прогнозируемые) деяния третьих лиц, в том числе и за эксцесс исполнителя. В связи с этим отдельные правоведы более оправданной считают позицию Международного уголовного суда в части определения доктрины сложного соисполнительства. В соответствии с указанной доктриной исполнителями (субъ- 
ектами) признаются любые лица, реализуемые запланированный умысел совместно. При этом они не выходят за рамки общего плана и своим поведением содействуют наступлению необходимого преступного результата. Такое соучастие признается признаком исключительного умышленного преступления. В случае же эксцесса исполнителя ответственность других соучастников исключается [9, с. 297].

По итогу вышеприведенного анализа развития института соучастия в международном уголовном праве следует отразить ряд аспектов и тенденций. Во-первых, данный институт находится в постоянном развитии. Указанное обстоятельство подтверждается наличием новейших научных исследований, в том числе решений недавних международных трибуналов, в частности по бывшей Югославии. В этом смысле обрисованная выше концепция совместной преступной деятельности имеет право на существование и закрепление в международном уголовном законодательстве. Заметим, однако, что указанная концепция тем не менее содержит определенные пробелы и противоречия. Полагаем, что в случае более детальной доработки концепции она в полном объеме может претендовать на отражение в итоговых решениях международных(ого) судов(а).

\begin{tabular}{|c|c|c|c|c|c|}
\hline -вторых, & если & говорить & $\mathrm{O}$ & видах & соучастников \\
\hline pmax & соучастия, & TO & & ине & международног \\
\hline
\end{tabular}
уголовного права отсутствует единая выработанная позиция. С одной стороны, отсутствие унифицированной «застывшей» теоретической точки зрения - это позитивный момент, поскольку уровень и новизна преступного транснационального сотрудничества иногда достигает серьезных глобальных размахов и фрорм и в этом случае возникает необходимость в проведении дополнительных серьезных исследований для выявления нестандартных признаков того или иного вида соучастника или фрормы их деятельности. С другой же стороны, система доктринальных и законотворческих взглядов требует некой системности и упорядочения, поскольку в целом ряде международных правовых актов, а также научных трудах приводятся порой дискуссионные, непроверенные практикой положения, что зачастую приводит к неразберихе в правотворчестве и в правоприменительной деятельности международных судов [10, с. 66].

\section{Ссылки}

1. Robert Cryer. An introduction to international criminal law and procedure. Cambridge University Press. Cambridge, 2007. 230 p.

2. Gary D. Solis. The Law of Armed Conflict: International Humanitarian Law in War. Cambridge University Press. Cambridge (Retrieved November, 14), 2010. 864 p. 
3. Соловьёв О. Г., Абросимов В. Е. Виды и формы соучастия в международном уголовном праве // Актуальные проблемы теории и истории правовой системы общества. 2019. № 18 (18). С. 132-141.

4. Смирнов Р. Ю., Савкина А. С. Уголовная ответственность за наемничество: историко-правовой анализ и место преступления в системе международного и отечественного права // Актуальные проблемы уголовного права на современном этапе (вопросы дифференциации ответственности и законодательной техники). 2019. № 8 (8). С. 120-129.

5. Устав Нюрнбергского трибунала, принятый решением Лондонской коноеренции от 8 августа 1945 года. URL: http://docs.cntd.ru/document/901737883 (дата обращения: 18.03.2021).

6. Панов В. П. Международное уголовное право: учебное пособие. М.: Инdppa-M, 1997. 320 c.

7. Спиридонов А. П. Классификация преступлений в международном уголовном праве // Известия вузов. Северо-Кавказский регион. Серия: Общественные науки. 2005. № 6. URL: https:// cyberleninka.ru/article/n/klassfikatsiya-prestupleniyv-mezhdunarodnom-ugolovnom-prave (дата обращения: 18.03.2021).

8. Кибальник А. Г. Некоторые проблемы понимания соучастия в решениях современных международных трибуналов // Международное уголовное право и международная юстиция. 2013. № 6. С. 3-6.

9. Schabas W. A. The UN International Criminal Tribunals: The Former Yugoslavia, Rwanda and Sierra Leone. Cambridge, 2006. 330 p.

10. Соловьев О. Г., Соколова О. В. Регламентация ответственности соучастников преступления в международном уголовном праве // Вестник Ярославского государственного университета им. П. Г. Демидова. Серия Гуманитарные науки. 2017. № 3 (41). C. 64-67. 